\title{
Innovación y Emprendedurismo
}

\author{
Innovation and Entrepreneurship
}

\author{
Graciela Pereyra Fausto ${ }^{a}$
}

\begin{abstract}
:
The different schools of economic thought have exposed their ideas to explain the sources of economic growth, one of these theories emerged in the early nineteenth century to respond because these economic cycles are presented. It was then that this great economist Joseph Alois Shumpeter appeared from an evolutionary perspective recognizes an economic agent over the whole crowd with the ability to do things differently in the production process, that is to say innovate which I call an entrepreneur currently in force in our entrepreneurial culture.
\end{abstract}

Keywords:

Innovation, entrepreneurship

\section{Resumen:}

Las escuelas del pensamiento económico han expuesto sus ideas para explicar las fuentes del crecimiento económico, una de estas teorías surgió a principios del siglo XIX para dar respuesta porque se presentan estos ciclos económicos. Fue entonces que a pareció este gran economista Joseph Alois Shumpeter desde un enfoque evolutivo reconoce a un agente económico sobre toda la muchedumbre con la capacidad de hacer las cosas distintas en el proceso de producción, es decir innovar al cual llamo emprend edor actualmente vigente en nuestra cultura emprendedora.

Palabras Clave:

innovación, emprendedurismo

\section{Introducción}

A mitad del siglo XVIII XVIII se desarrolló la primera teoría económica el mercantilismo teniendo como base el comercio exterior y la ganancia derivado de este la acumulación de metales preciosos explicaba la riqueza del país, todo esto en los albores del precapitalismo o capitalismo comercial en oposición al mercantilismo surge la fisiocracia que es gobierno de la naturaleza, su máximo representante Adam Smith, un país se tenía que dedicarse a la agricultura, para generar riqueza, la escuela clásica surge con la obra de este último autor "La causa de las fuentes de la riqueza" en 1776, este vivió en la época de la revolución industrial y por ende al capitalismo industrial. Posteriormente, aparece Carlos Marx con su materialismo histórico para explicar la lucha de clases en los distintos modos de producción, sea taller, cooperativa, manufactura o industria.

A finales del siglo XIX aparece una ruptura con los clásicos la escuela neoclásica en 1870 que se encarga del estudio del comportamiento del consumidor y el intercambio, fue a principios del siglo XX cuando se inicia la fase superior del capitalismo el imperialismo o capitalismo financiero o monopolístico, donde se da inicio a la competencia imperfecta

\section{Origen del empresario}

Hasta entonces el señor feudo paso a ser comerciante, posteriormente burgués había obtenido las ganancias de la repetición de un ciclo productivo tras otro, ya sea por el método de feudo-vasallaje, maestro-aprendiz, burgués-obrero apropiándose del trabajo excedente mediante la plusvalía absoluta en forma de extensión de la jornada de trabajo o plusvalía relativa intensificación por medio de la máquina, si estas relaciones laborales generaban ganancia al primero en detrimento del segundo. ¿Por qué la tasa de ganancia estaba disminuyendo? En el momento en que la industrialización maduraba. Fue Joseh Alois Shumpeter quien en su obra retoma el análisis de la escuela histórico alemana y de los neoclásicos, realiza el análisis estudiando el comportamiento de ese burgués que se había convertido en un agente parasito como 
supone Keynes. El capitalismo no caí por el subconsumo como supone Marx sino por la falta de capacidad de los dueños de la producción de innovar.

La teoría de Shumpeter "asume la ausencia de cambio (aunque no de crecimiento)". Esto se debe a la falta de innovación que la define como "hacer las cosas de forma diferente en el ámbito de la vida económica" (Shumpeter.J., 2010)

Esta teoría está vigente actualmente, como la fecha en que se daría a conocer, cabría en ese entonces distinguir actualmente la diferencia entre empresario y emprendedor el primero es metódico, trabaja con resultados, el segundo trabaja con ideas y personas. Desde el punto de vista cognitivo el empresario tiene a procesar información congruente mientras el emprendedor procesa información no congruente en un tiempo menor que el primero.

Actualmente, en el país se fomenta la cultura del emprendedurismo mediante el Instituto Nacional del Emprendedor creado en 2013.

Uno de los indicadores que mide la innovación tecnológica es el número de patentes de acuerdo con él (Banco de Desarrollo de América Latina) en consecuencia se supone una relación positiva entre el nivel tecnológico y el crecimiento económico.

A continuación se especifican el número de patentes de acuerdo con (INEGI) en nuestro país y el pronóstico del PIB (Banxico).

El registro de patentes totales por cada millón de habitantes, se tiene para el año 2010 se registraban 82.65 patentes, para 2011 se incrementó a 99.5 para el siguiente año en 2012 fue el mejor año con 10.5 patentes, sin embargo, para 2013 existió una disminución con 87.32 a partir de este año empieza la disminución con $81.87,76.95$ y 70.55 y finalmente para el año 2017 se tiene 68.61 patentes, el mayor pronóstico de la variación porcentual real anual del PIB en el año 2011 con 5.22 .

Para el año 2012 donde se tiene un mayor número de patentes registradas con 105.44, se presenta una disminución del pronóstico de crecimiento para el PIB de 3.90 , esto se traduce aunque aumentaron el número de patentes no se traduce en un mayor crecimiento económico, al trascurrir los años el número de patentes disminuye y la variación de crecimiento es menor de un año con respecto a este. Así mismo, el Global Entrepreneurship para el año 2015 México tiene una tasa de innovación de 18.31, y de 22.93 para 2017 siendo el promedio regional es de 22.93, y el promedio global es de 26.50. (Global Entrepreneurship GEM). Aunque ha aumentado en porcentaje la capacidad de emprender, las innovaciones no se registran y en consecuencia no llegan a impactar en el crecimiento económico. De igual forma se tiene una percepción de oportunidad de innovar de apenas 36.38en 2017. Finalmente México tiene una gran cultura pero un espíritu emprendedor aun naciente.

\section{Referencias}

[1]Banco de Desarrollo de América Latina. (s.f.). Recuperado el 10 de Abril de 2019, de www.caf.com

[2]Banxico. (s.f.). Pronoósticos de la variación porcenual real anual del PIB en el año indicado.Recuperado el 10 de Abril de 2019

[3]Global Entrepreneurship GEM. (s.f.). Recuperado el 7 de Abril de 2019, de http://www.gemconsortium.org

[4]INEGI. (s.f.). INC. Series originales resgistro de patentes totales por cada millón de habitantes.Recuperado el 10 de Abril de 2019, de htpp://inegi.org.mx

[5]Shumpeter.J. (2010). ¿Puede sobrevivir el capitalismo? La destrucción creativa y el futuro de la economía global. España: Colección entre líneas. ISBN: 978-84-937709-8-3 